\title{
Effect of Heat Treatment on Characteristics of Plasma Sprayed Hydroxyapatite Coatings
}

\author{
Chun-Cheng Chen ${ }^{1}$ and Shinn-Jyh Ding ${ }^{2}$ \\ ${ }^{1}$ Dental Department, Chung-Shan Medical University Hospital, Taichung 402, Taiwan, R. O. China \\ ${ }^{2}$ Institute of Oral Materials Science, Chung-Shan Medical University, Taichung 402, Taiwan, R. O. China
}

\begin{abstract}
Bioactive hydroxyapatite (HA)-coated implants plasma sprayed on Ti6Al4V substrates have been widely used in load-bearing applications because of their biocompatibility and their intimate contact with bone. The improvement of the characteristics of HA coatings is concerned. The purpose of this work was to evaluate corrosion behavior and bond strength of HA coatings after post-deposition heat treatment at 500-700 ${ }^{\circ}$. The results indicated that the heat treatment led to recrystallization of amorphous calcium phosphate of as-sprayed HA coatings. The reduction of layer defects associated with plasma-sprayed coatings and the enhancement of the resistance to corrosion took place after heat treatment. Bond strength of the heat-treated coatings was sensitive to the treatment temperature. It is concluded that the heat treatment at $600^{\circ} \mathrm{C}$ for $1 \mathrm{~h}$ in air, endowing with increased crystallinity and the reduced defects without significantly reduced bond strength, provided a better corrosion protection than the other two treatment temperatures.
\end{abstract}

(Received December 12, 2005; Accepted January 30, 2006; Published March 15, 2006)

Keywords: plasma spray, hydroxyapatite, heat treatment, coating, corrosion, bond strength

\section{Introduction}

The chemical and phase composition of hydroxyapatite (HA) is similar to the mineral component of bone and tooth. ${ }^{1,2)}$ Over the past 15 years, HA coatings plasma sprayed on metallic substrates have been widely used in clinical loadbearing implant applications because of their biocompatibility and their intimate contact with bone. ${ }^{2-6)}$ Plasma spraying is the most widely used technique to deposit HA coatings due to its process feasibility. However, during plasma spraying process HA coating crystallinity decreases, phase composition of the coating is subjected to change, and residual stresses occur within the coating as a result of high temperatures. ${ }^{7-10)}$ Hence, plasma-sprayed HA-coated implants are essentially composed of a mixture of crystalline, amorphous, and non-apatite phases such as $\mathrm{Ca}_{3}\left(\mathrm{PO}_{4}\right)_{2}(\mathrm{TCP})$, $\mathrm{Ca}_{4}\left(\mathrm{PO}_{4}\right)_{2} \mathrm{O}$ (TTCP) or even $\mathrm{CaO}$. The presence of TCP and TTCP phases would enhance the resorption process of HA coating leading to implant instability. ${ }^{11)}$ In addition, the thick coatings produced by plasma spray often exhibited porosity that weakened the interfacial strength and provided an easy fracture path for adhesion failure. ${ }^{11)}$ Pores and other coating imperfections reduced the corrosion resistance. ${ }^{12,13)}$

As far as the longevity and safety of coating implants are concerned, the coating with higher crystallinity and fewer defects may be preferentially considered. HA coatings with higher crystallinity yielded a decreased dissolution rate ${ }^{14,15)}$ and enhanced rate of cell proliferation. ${ }^{16)}$ As suggested by Darimont et al., the implants in trabecular or cancellous bone would require coatings with a very high crystallinity. ${ }^{17)}$ For improving the quality of plasma sprayed coatings, the heat treatment is sometimes a used method to increase coating crystallinity and reduce the residual stress of HA-based coatings, $5,6,15,18-23)$ aside from optimizing plasma spray processing and altering material composition. ${ }^{14,24,25)}$ Caulier et al. confirmed in a goat animal model that heat-treated HA plasma-sprayed implant showed less reduction in coating thickness than as-sprayed HA coatings. ${ }^{6)}$ In a recent paper, ${ }^{26)}$ we found that the $\mathrm{HA}$ coatings heat-treated at $650^{\circ} \mathrm{C}$ gave rise to recrystallization of amorphous calcium phosphate and the conversion of non-apatite phases into apatite as well as showing a higher corrosion resistance. Li et al. demonstrated that the complete crystallization of the amorphous phase of high-velocity oxy-fuel sprayed HA coatings occurred at approximately $700^{\circ} \mathrm{C} .^{27)}$

So far, most studies have concentrated on the changes in purity and crystallinity of plasma-sprayed HA coatings, relatively few data on the changes in the mechanical properties and corrosion behavior were reported. The purpose of this study is to study the characteristics of plasma sprayed HA coatings, such as coating crystallinity, corrosion behavior, and bond strength, when subjected to heat treatment at different temperatures.

\section{Experimental Procedure}

\subsection{Plasma spraying processing}

Commercial HA powder (AMDRY 6021, Plasma Technik A.G., Wohlen, Switzerland) with particle size between 44 and $149 \mu \mathrm{m}$ was used in this study. Commercially available plates of Ti6Al4V alloy $(100 \times 10 \times 3 \mathrm{~mm}$ thick $)$ were used as the substrate material. Prior to plasma spray, the substrate surface was mechanically polished to \#1200 grit level, cleaned and sandblasted with $450 \mu \mathrm{m} \mathrm{SiC} \mathrm{particles.} \mathrm{To} \mathrm{obtain}$ a uniform coating, the substrate was mounted on a disk that could rotate during spraying in air using a Plasma-Technik A3000 system (Plasma Technik A.G., Wohlen, Switzerland). The parameters used included a plasma power of $37 \mathrm{~kW}$ and plasma gas of $\mathrm{Ar}$ and $\mathrm{H}_{2}$ with the flow rate of 45 and $11 \mathrm{~L} /$ min, respectively. A spray distance of $130 \mathrm{~mm}$ and spray angle of $90^{\circ}$ were chosen. The powder was transported at a feed rate of $0.02 \mathrm{~kg} / \mathrm{min}$ with $\mathrm{Ar}$ as a carrier gas. Monolithic HA coating of about $100 \mu \mathrm{m}$ thick was fabricated.

\subsection{Heat treatment}

In order to study the effect of heat treatment, the as- 
sprayed HA coatings were heat-treated at 500,600 and $700^{\circ} \mathrm{C}$ for $1 \mathrm{~h}$ each at a heating rate of $5^{\circ} \mathrm{C} / \mathrm{min}$ in an air-circulated furnace, and then the furnace cooling to room temperature.

\subsection{Phase composition and microstructure analyses}

Phases of all coatings were analyzed by an X-ray diffractometer (Shimadzu XD-D1, Kyoto, Japan) operated at $30 \mathrm{kV}$ and $30 \mathrm{~mA}$. The crystallinity was estimated by the area ratio of three major peaks, (211), (112) and (300), of the coated samples to that of the HA powder used for the plasma spray. A Fourier transform infrared (FTIR) spectroscopy (Bomem DA8.3, Hartman \& Braun, Canada) in reflection absorption mode with a spectral resolution of $1 \mathrm{~cm}^{-1}$, was used to characterize the various functional groups on the coating surface. The microstructure was characterized under field emission scanning electron microscope (FESEM) (Hitachi S-4200, Hitachi, Tokyo, Japan). Specimens for cross-sectional microscopy were prepared by mounting the coated specimens in epoxy resin, followed by polishing through $1 \mu \mathrm{m}$ alumina.

\subsection{Electrochemical test}

The commonly-used Hanks' balanced salt solution (HBSS), recommended by Pourbaix, ${ }^{28)}$ has an ionic composition similar to that of human plasma, which adjusted to an initial $\mathrm{pH}$ of 7.4. The electrochemical measurements carried out on the coated samples with a surface area of $1 \mathrm{~cm}^{2}$ were open circuit potential (OCP)-time measurements and potentiodynamic polarization in HBSS, using a conventional threeelectrode cell connected with a CHI 660A electrochemical system (CH Instrument, Austin, Texas). For OCP measurement, only two electrodes (working electrode and reference electrode) were involved, while for potentiodynamic polarization method a conventional three-electrode cell was used. A saturated calomel reference electrode (SCE) and a platinum counter electrode were employed. The sample surface was cleaned by distilled water. Deaerated conditions under $\mathrm{N}_{2}$ gas purging and a temperature of $37^{\circ} \mathrm{C}$ were used for in vitro experiments. The evaluation of potentiodynamic polarization was started after immersion in HBSS for $1 \mathrm{~h}$. The scanned potential range varied from $-1 \mathrm{~V}$ up to $2 \mathrm{~V}$ toward the anodic direction at a sweep rate of $0.5 \mathrm{mV} / \mathrm{s}$ in the Tafel mode. Six measurements were performed for each group. Corrosion potential, corrosion current and polarization resistance were provided after being analyzed by the builtin software.

\subsection{Bond strength measurement}

Bond strength (or adhesive strength) of the HA coatings before and after heat treatment was used to represent the present pull-out test results using an EZ-Test machine (Shimadzu, Kyoto, Japan) at a loading rate of $0.5 \mathrm{~mm} / \mathrm{min}$. In doing the testing, a $2.7 \mathrm{~mm}$ dia. aluminum pull stud (Quad Group, Spokane, WA) was bonded to the coated surface with a solid epoxy and then cured at $150^{\circ} \mathrm{C}$ for $1 \mathrm{~h}$ in oven. After the coated specimen/stud assembly was gripped on a platen, the stud was then pulled down against the platen until failure. The maximum fracture force can be recorded and averaged to obtain the mean value and standard derivation. The number of measurements is sixteen for each group.

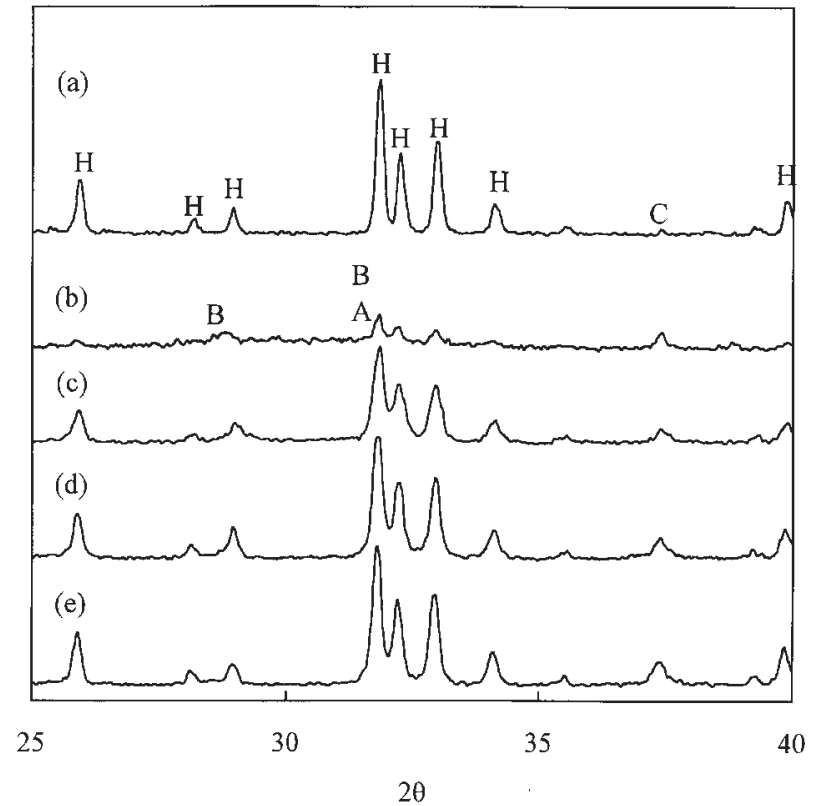

Fig. 1 XRD patterns of the HA powder (a), as-sprayed coating (b), and heat-treated coatings at $500^{\circ} \mathrm{C}(\mathrm{c}), 600^{\circ} \mathrm{C}(\mathrm{d})$, and $700^{\circ} \mathrm{C}(\mathrm{e}) .(\mathrm{H}$ : apatite; A: $\alpha$-TCP; B: $\beta$-TCP; $\mathrm{C}: \mathrm{CaO})$.

\subsection{Statistical analysis}

One-way ANOVA statistical analysis was used to evaluate the statistical significance of the bond strength and electrochemical data. A Scheffe' multiple comparison test was used to determine the significance of the deviations in bond strength and electrochemical data of the coated samples without and with heat treatment. In all cases, results were considered statistically different when $p<0.05$.

\section{Results and Discussion}

\subsection{Phase composition and microstructure}

Figure 1 shows the XRD patterns of the HA powder, assprayed coating and heat-treated coatings. The as-sprayed coating was the characteristic of an apatitic structure of lower crystallinity than HA powders with a reduction of $63 \%$. Besides the broadening of apatite peaks and increased intensity of $\mathrm{CaO}$ phase, TCP phases were observed in the as-sprayed sample. The high temperature involved in plasma spray process had obviously enhanced the decomposition of apatite as well as chemical reactions within HA phase. Compared with the as-sprayed HA coating, heat-treated coatings had a higher apatite crystallinity and a smaller amount of TCP phases but the retention of $\mathrm{CaO}$. Using the integrated area of (211), (112) and (300) peaks of apatite phase, the crystallinity of heat-treated coatings was about three-fold greater than that of the as-sprayed coating and increased with the increasing treatment temperature.

Figure 2 shows FTIR reflection spectra of all coatings. The broad bands at $970-1130 \mathrm{~cm}^{-1}$ in FTIR reflection spectra of as-sprayed coatings, probably resulted from overlaping apatite, $\alpha$-TCP and $\beta$-TCP signals, were attributed to $\mathrm{HPO}_{4} / \mathrm{PO}_{4}$ functional groups. ${ }^{29,30)}$ The bands between 603 and $574 \mathrm{~cm}^{-1}$ were suggested to arise from the vibrational mode of $\mathrm{PO}_{4}$ groups. ${ }^{30)}$ After post-deposition treatment in air 


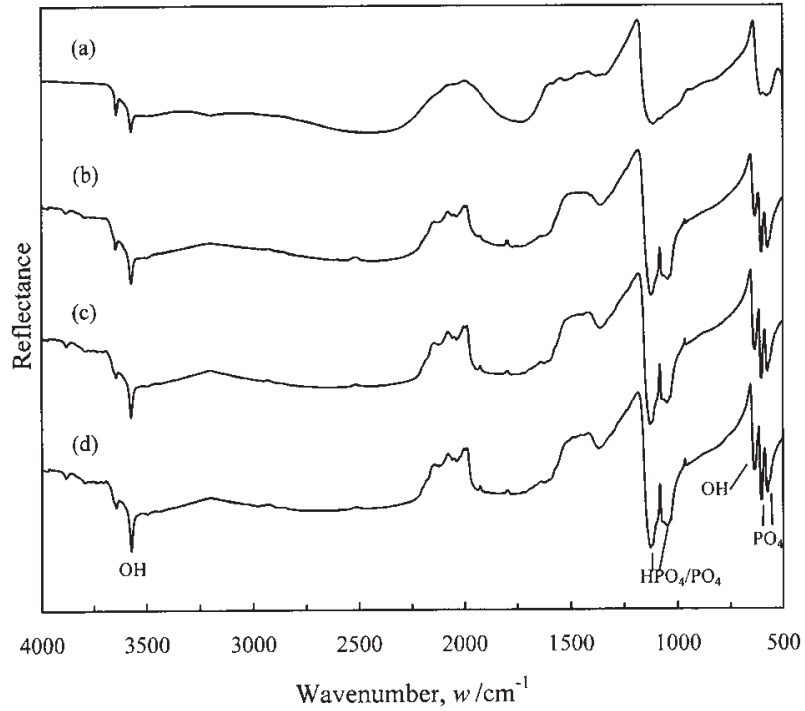

Fig. 2 FTIR spectra of the as-sprayed coating (a) and heat-treated coatings at $500^{\circ} \mathrm{C}(\mathrm{b}), 600^{\circ} \mathrm{C}(\mathrm{c})$, and $700^{\circ} \mathrm{C}(\mathrm{d})$.

at $500-700^{\circ} \mathrm{C}$, the sharper $\mathrm{PO}_{4}$ stretching mode at 603 and $574 \mathrm{~cm}^{-1}$ and the two more appreciable adsorption bands at $970-1130 \mathrm{~cm}^{-1}$ demonstrated an increased crystallinity. The appearance of the absorption band at $630 \mathrm{~cm}^{-1}$ and sharper band at $3572 \mathrm{~cm}^{-1}$ with an indication of the vibrational modes of $\mathrm{OH}$ groups ${ }^{29)}$ suggested the reestablishment of a hydroxylated HA structure when the as-sprayed HA coating was heat-treated in air. The atmospheric moisture can react with amorphous oxyapatite so that $\mathrm{OH}$ groups recovered and promoted the reconstitution of amorphous oxyapatite into crystalline oxyhydroxyapatite. ${ }^{18,19)}$
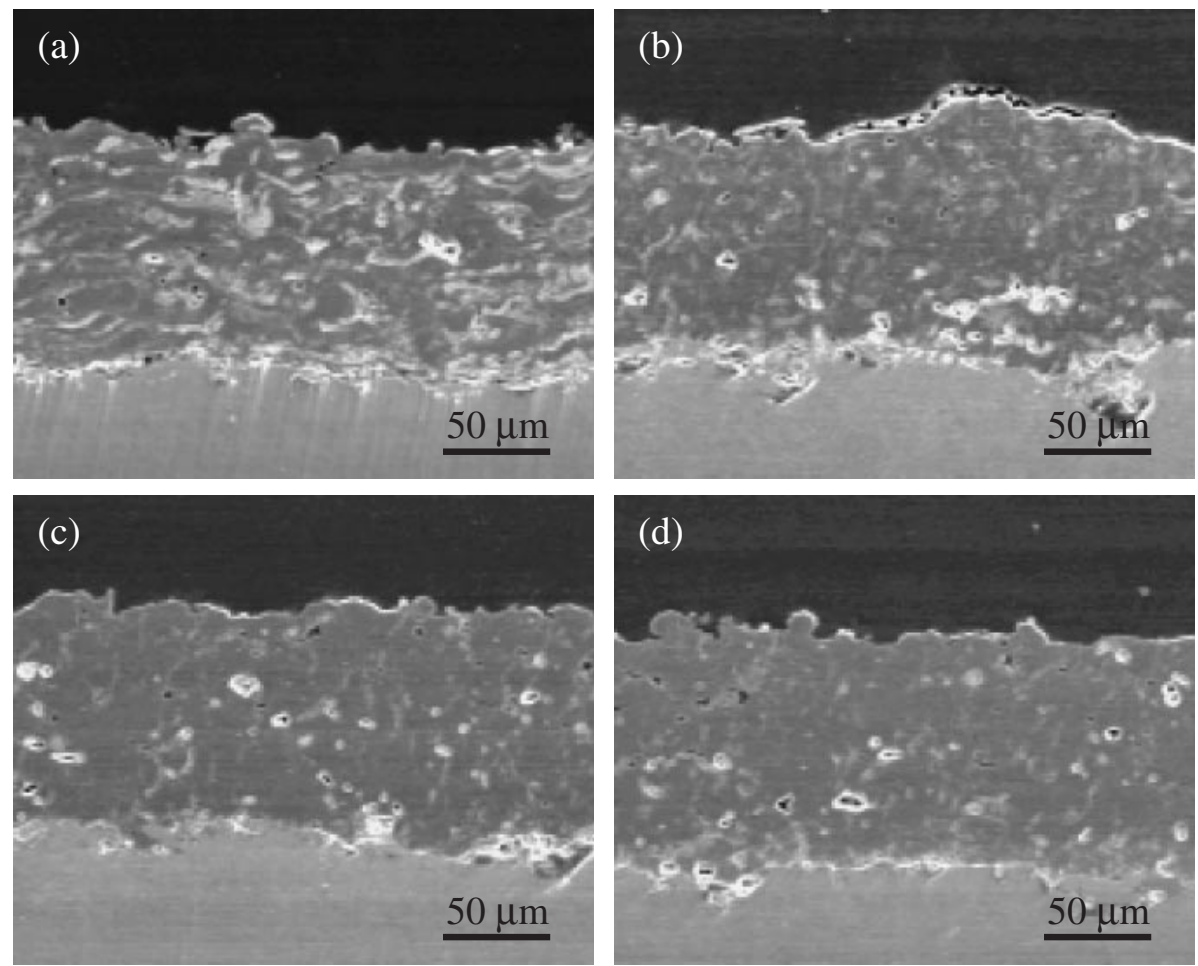

Fig. 3 Cross-sectional SEM micrographs of the as-sprayed coating (a) and heat-treated coatings at $500^{\circ} \mathrm{C}(\mathrm{b}), 600^{\circ} \mathrm{C}(\mathrm{c})$, and $700^{\circ} \mathrm{C}(\mathrm{d})$.

In addition to enhancing coating crystallinity, the heat treatment could effectively convert non-apatite phases (TCP) into apatite, consistent with a previous study. ${ }^{20,26)}$ Like other amorphous phases, ${ }^{18,19)}$ the amorphous calcium phosphate in the as-sprayed samples is thermodynamically metastable and an appropriate thermal treatment could induce recrystallization of them. Although higher-temperature treatment can help hasten the amorphous-crystalline phase transformation, it is practical to use lower heat-treatment temperatures to avoid serious irreversible structural and property changes to the Ti alloy substrate. ${ }^{31)}$ In this study $600^{\circ} \mathrm{C}$ seems to be ideal as almost complete crystallization of HA (86\% of HA powder) was achieved.

SEM micrographs showed that the appearance of the coating surfaces after heat treatment were similar to those of as-sprayed coatings, which had well-flattened splats and shiny glassy films and irregularly-shaped particles, due to that the crystallization of amorphous phases did not influence the surface morphology under low magnification. ${ }^{24)}$ Randomly distributed pores of different sizes and microcracks were also observed. During plasma spraying, small size powder was completely melted and formed a glassy phase during fast cooling, while larger size powder was only partially melted resulting in a rough, irregularly-shaped surface morphology. ${ }^{32,33)}$ This observation is consistent with the earlier-discussed XRD results (e.g. broadening in apatite peaks). In Fig. 3 the cross-sectional SEM micrographs showed that the thickness of all coatings was roughly $100 \mu \mathrm{m}$. The "flake-type" of layer defects between the splats within coatings are observed tending to be parallel to the coating surface [Fig. 3(a)]. Besides, there were a lot of perpendicular defects inside the coatings, e.g., pores and cracks. These plasma spray-induced layer defects were 


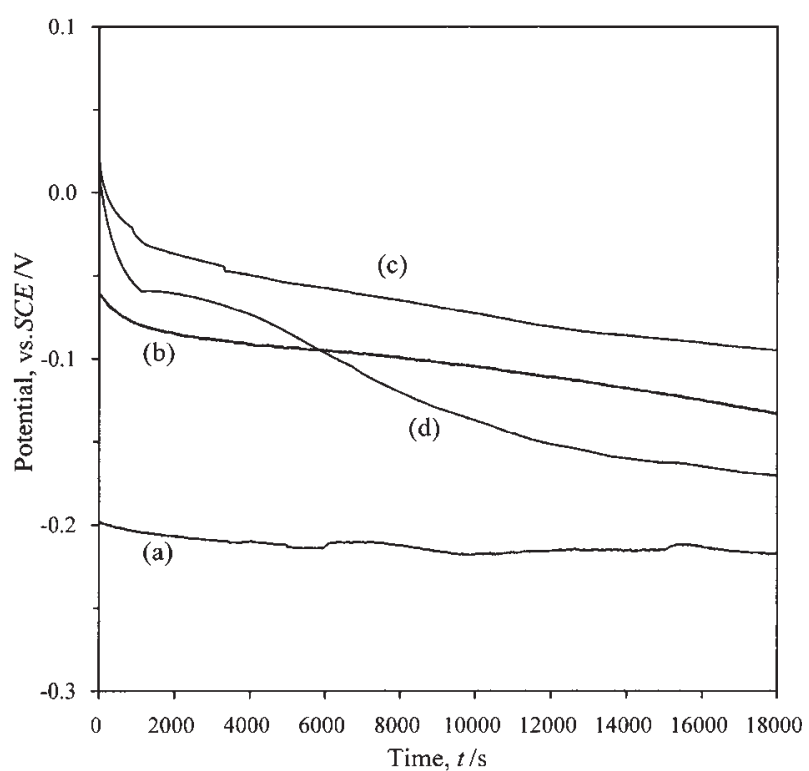

Fig. 4 Open circuit potential-time measurements in deaerated HBSS of the

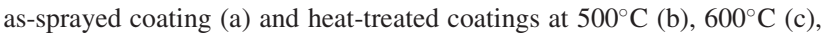
and $700^{\circ} \mathrm{C}(\mathrm{d})$.

frequently observed in plasma sprayed HA and other coatings. ${ }^{25,34)}$ The "flake-type" regions were examined to be amorphous with micro-Raman spectroscopy and nanoindentation techniques. ${ }^{35)}$ After post-deposition heat treatment, such microstructure of plasma-sprayed coatings were improved. It seems that change in porosity can be deduced from SEM pictures between as-sprayed and crystallized coatings. The changes in CTE (coefficient of thermal expansion) caused by the annealing might more or less contribute to microstructure changes because different phases possess different CTEs (HA: $11.5 \times 10^{-6}$, TCP: $14.2 \times$ $\left.10^{-6 \circ} \mathrm{C}^{-1}\right) .{ }^{9,36)}$ In addition, this can be explained in terms of the heat treatment during which the atoms gained high kinetic energy and diffused much faster than at room temperature. ${ }^{19)}$ The faster diffusion of the atoms speeded up the phase transition and affected the flake-type appearance.

\subsection{Electrochemical test}

The OCP-time plots for the coating samples heat-treated at 500,600 and $700^{\circ} \mathrm{C}$ as a function of time along with the assprayed coating are shown in Fig. 4. It seems that the assprayed HA coating is in a steady state possibly due to the apatite precipiatation, ${ }^{26)}$ although having a more negative initial potential of $-0.198 \mathrm{~V}$. On the contrary, all heat-treated samples showed a higher initial OCP, tending to a decreased potential, in particular, for the coating heat-treated at $700^{\circ} \mathrm{C}$.

Figure 5 shows the typical potentiodynamic polarization curves of the plasma-sprayed coatings without and with heat treatment in deaerated HBSS at $37^{\circ} \mathrm{C}$. It can be seen all coatings indicated a breakdown potential in the range between 0.5 and $1.0 \mathrm{~V}$. All electrochemical parameters, including corrosion potential $\left(E_{\text {corr }}\right)$, current density $\left(i_{\text {corr }}\right)$, and polarization resistance $\left(R_{\mathrm{p}}\right)$, of coating samples are also compiled in Table 1 . As corrosion potential was concerned, there are significant differences $(p<0.05)$ among all test samples. After heat treatment at 500, 600 and $700^{\circ} \mathrm{C}$,

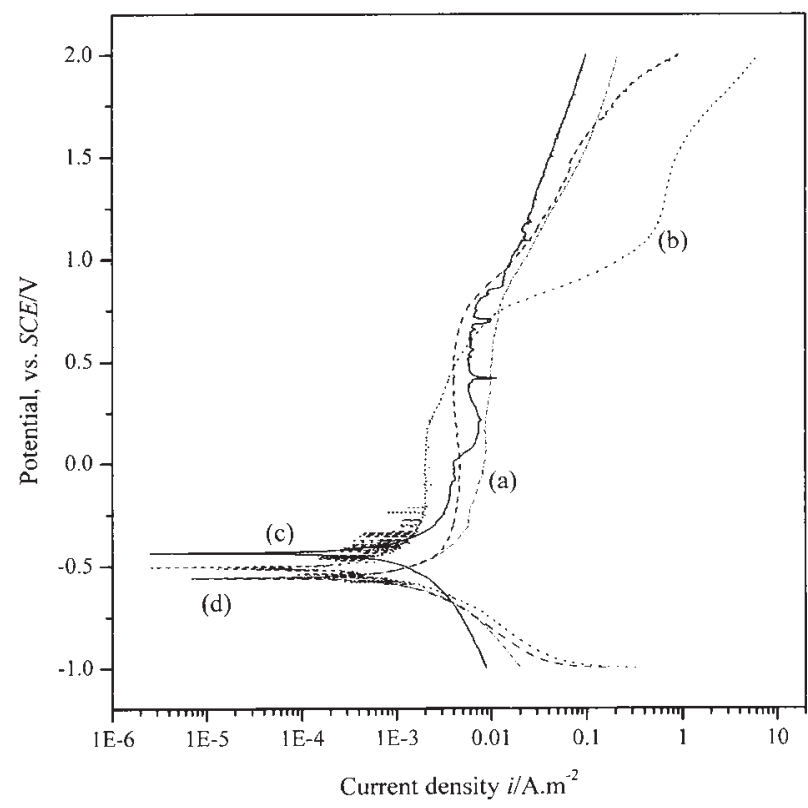

Fig. 5 Typical polarization curves of the as-sprayed coating (a) and heattreated coatings at $500^{\circ} \mathrm{C}(\mathrm{b}), 600^{\circ} \mathrm{C}(\mathrm{c})$, and $700^{\circ} \mathrm{C}(\mathrm{d})$ in deaerated $\mathrm{HBSS}$ at $37^{\circ} \mathrm{C}$.

Table 1 Mean and standard derivation values of electrochemical parameters of the as-sprayed coating and heat-treated HA coatings at different temperatures after electrochemical test.

\begin{tabular}{ccccc}
\hline \multicolumn{1}{c}{ Coating } & \multicolumn{1}{c}{$E_{\text {corr }}(\mathrm{V})$} & $i_{\text {corr }}\left(\times 10^{-3} \mathrm{~A} \cdot \mathrm{m}^{-2}\right)$ & $R_{\mathrm{p}}\left(\Omega \cdot \mathrm{m}^{2}\right)$ \\
\hline As-sprayed & & $-0.57 \pm 0.06$ & $2.22 \pm 0.60$ & $36 \pm 9$ \\
& $500^{\circ} \mathrm{C}$ & $-0.61 \pm 0.08$ & $1.50 \pm 0.69$ & $61 \pm 10$ \\
Heat-treated & $600^{\circ} \mathrm{C}$ & $-0.48 \pm 0.06$ & $1.12 \pm 0.33$ & $81 \pm 9$ \\
& $700^{\circ} \mathrm{C}$ & $-0.62 \pm 0.06$ & $1.94 \pm 0.26$ & $64 \pm 12$ \\
\hline
\end{tabular}

corrosion potentials of the heat-treated samples were found to be $-0.61,-0.48$ and $-0.62 \mathrm{~V}$ (vs. SCE), respectively. Moreover, via Scheffe' multiple comparison test the difference in corrosion potential between $600^{\circ} \mathrm{C}$-sample and $500^{\circ} \mathrm{C}$-sample is found $(p<0.05)$, also between $600^{\circ} \mathrm{C}$ sample and $700^{\circ} \mathrm{C}$-sample $(p<0.05)$. On the contrary, there is no significant difference $(p>0.05)$ in corrosion potential between as-sprayed coating and heat-treated coating at $600^{\circ} \mathrm{C}$. The results confirmed that $600^{\circ} \mathrm{C}$-treatment HA coatings exhibited a significantly better corrosion-resistant ability than all the other coatings by virtue of more noble corrosion potential, although all polarization curves were characterized by a very similar trend.

The corrosion current density and polarization resistance of the samples were determined from the potentiodynamic polarization curves using Tafel extrapolation method. As for current density, it could be found that the average values of the heat-treated coatings of between 1.12 and $1.94 \times 10^{-3}$ $\mathrm{A} / \mathrm{m}^{2}$, which lower than that of the as-sprayed coating $\left(2.22 \times 10^{-3} \mathrm{~A} / \mathrm{m}^{2}\right)$, were dependent on treatment temperature, revealing the significant difference $(p<0.05)$. Previous studies have reported similar behaviour. ${ }^{26)}$ In contrast to current density, there was an increase in the $R_{\mathrm{p}}$ values about two times, representing that heat treatment favored the coatings a better resistance to corrosion. The polarization 
resistance is a parameter correlated to the corrosion rate. The higher the polarization resistance, the lower the corrosion rate was on the coating when exposed to physiological solution. ${ }^{37)}$

The critical factors affecting the corrosion characteristics of coatings are their quality (crystallinity, purity, residual stress and ion substitution in the apatite lattice) and structure. ${ }^{37-42)}$ The porosity is a characteristic of plasma sprayed coatings and strongly affects their corrosion behaviours. Generally speaking, the corrosion rate increases with increasing porosity in the coatings. ${ }^{41)}$ The electrolyte infiltrates into the inner portion of the coating through the structural imperfections such as pores and cracks or pinholes existing in the coating and comes into contact with the deeper portion of the coating, ${ }^{42)}$ causing corrosion. The polarization resistance $\left(R_{\mathrm{p}}\right)$ obtained can be used to determine the porosity that corresponds simply to the ratio of the polarization resistance of the uncoated substrates and the coated samples. ${ }^{38,39)}$ Using a modified equation, the ratio of $P_{\mathrm{s}} / P_{\mathrm{hs}}=$ $R_{\mathrm{p}, \mathrm{hs}} / R_{\mathrm{p}, \mathrm{s}}$ can be used to represent the porosity change, where $P_{\mathrm{S}}$ and $P_{\mathrm{hs}}$ are the porosity of the as-sprayed and heat-treated coatings, $R_{\mathrm{p}, \mathrm{s}}$ an $R_{\mathrm{p}, \mathrm{hs}}$ the polarization resistance of the assprayed and heat-treated coatings, respectively. To substitute the obtained $R_{\mathrm{p}}$ values into the above-mentioned equation, it is obvious that $P_{\mathrm{s}} / P_{\mathrm{hs}}$ is approximately two, indicating that the positive effect on the reduction of the porosity occurred in the heat-treated samples. ${ }^{25,34)}$ This was because that the heat treatment apparently reduced the plasma spray-induced flake-type structures, as described earlier in morphology change, resulting in heat-treated coating possessing a higher corrosion-resistant ability. More importantly, the in vitro electrochemical test results indicated that $600^{\circ} \mathrm{C}$-treatment coatings had a more beneficial and desired effect on corrosion behavior than the as-sprayed and the other two hea-treated samples at 500 and $700^{\circ} \mathrm{C}$ from the $R_{\mathrm{p}}$ and corrosion potential points of view.

\subsection{Bond strength}

The bonding strength of the HA coating to metallic substrate and the quality of the coating itself are always concerned in determining the performance and reliability of HA-coated implants. Bonding strength test results of the assprayed coating and the three heat-treated coatings are shown in Fig. 6. It can be seen that bond strength values of the heattreated coatings depended on treatment temperature. The bond strength of the as-sprayed coatings was 14.2 MPa. After heat treatment at 500,600 and $700^{\circ} \mathrm{C}$, the value became 10.8 , 13.9 and $7.7 \mathrm{MPa}$, respectively. The differences in bond strength values between as-sprayed and heat-treated coatings were statistically significant $(p<0.05)$. The statistical analysis using Scheffe's multiple comparison test showed that bond strength of $700^{\circ} \mathrm{C}$-treatment coatings significantly declined by about $46 \%$, but there is not significantly different between the as-sprayed and $600^{\circ} \mathrm{C}$-treatment coatings.

Many investigations have reported that bond strength of the coatings was apparently related to different deposition techniques and post-treatment parameters. ${ }^{5,21,24,27)}$ For example, Tsui et al. ${ }^{21)}$ found that heat treatment at $700^{\circ} \mathrm{C}$ for $1 \mathrm{~h}$ was effective in enhancing crystallinity, the $\mathrm{OH}^{-}$ion content and the purity of plasma sprayed HA coatings. However, a

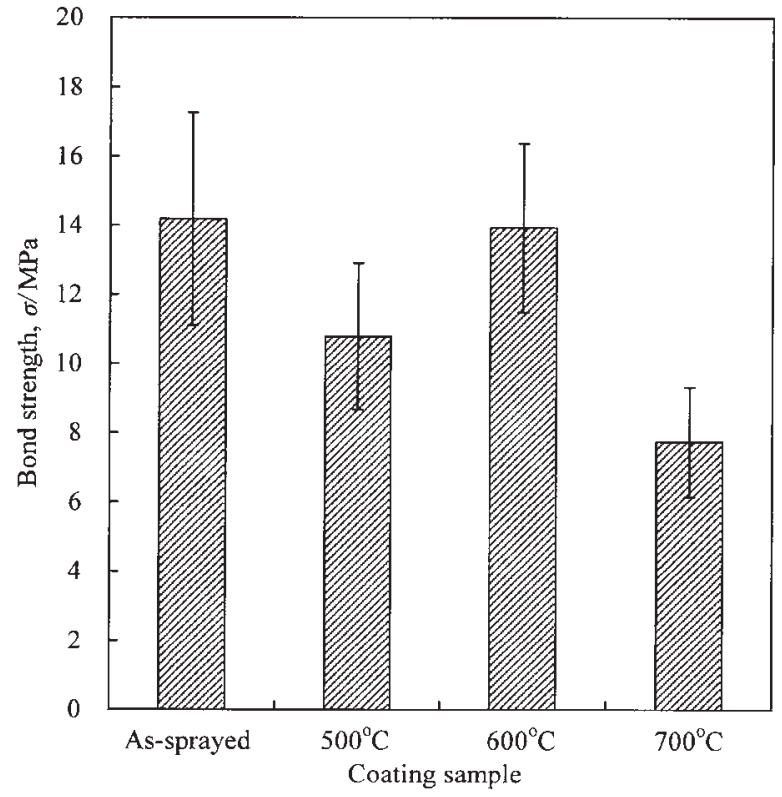

Fig. 6 Bond strength of the as-sprayed coating and heat-treated coatings.

significant drop in adhesion occurred on heat-treated coatings sprayed at high powers of $36 \mathrm{~kW}$. Similarly, Lynn and DuQuesnay reported that heat treatment of plasma sprayed $\mathrm{HA}$ coatings at $400^{\circ} \mathrm{C}$ for $90 \mathrm{~h}$ significantly reduced their fatigue resistance due to stress relief in the titanium substrate. ${ }^{22)}$ In contrast, Li et al. ${ }^{27)}$ suggested that the heat treatment at $750^{\circ} \mathrm{C}$ for $30 \mathrm{~min}$ is beneficial for the improved strength, as well as fracture toughness of high-velocity oxyfuel sprayed HA coatings, because the crystallization of the amorphous phase and the chemical reaction at the interface induced by the heat treatment. According to Burgess et al. ${ }^{5)}$ their hydrothermal post-plasma spray process did not affect the bond strength of HA coating to the metal substrate. As suggested by Brossa et al. ${ }^{43)}$ the variations in bond strength can be ascribed to different CTE of Ti6Al4V $(8.9 \times$ $\left.10^{-6 \circ} \mathrm{C}^{-1}\right)$ and of hydroxyapatite $\left(11.5 \times 10^{-6 \circ} \mathrm{C}^{-1}\right),{ }^{9}$ and a progressive oxidation of the metallic substrate caused by traces of oxygen, which has been proven in the literature. ${ }^{22)}$

As for the present study, in the case of heat-treated samples at $600^{\circ} \mathrm{C}$, we suggested that the microstructure changes in the reduction of the porosity and the splats bonding within the coating layer may positively contribute to the bond strength. On the contrary, when crystallization and phase transformations occur, the stresses caused by the associated volume change orinigating from the transformation of various nonapatite phases to apatite is superimposed on the residual stresses already present, which can induce cracking inside the deposit. $^{21,44)}$ Many studies claimed that the coatings adjacent to substrate have more amorphous phase..$^{8,35)}$ When heattreated at higher temperature such as $700^{\circ} \mathrm{C}$, the regions near the substrate may result in a larger amount of cracks caused by the large volume shrinkage during the crystallization and phase transformation, in turn, detrimental to the bonding strength of the coating, although possessing a higher crystallinity. Hence, in this work, the differences in the bonding strengths can be explained in terms of the stress relief and microstructure changes. 


\section{Conclusions}

The microstructural and chemical inhomogeneity in plasma-sprayed HA coating may affect its properties including interfacial bond strength and dissolution behavior. The results of the comparative study indicated that the heattreated HA coatings obtained had a higher crystallinity by a factor of 3-4 but temperature-sensitive bond strength. In addition, the heat-treated HA coatings had a better corrosionresistant ability with an increased polarization resistance value by approximately two times as compared to as-sprayed samples. Improved corrosion resistance was due to a coating surface modification with higher crystallinity and less dissoluble non-apatite phases (TCP), as well as a reduction of coating defects when plasma-sprayed coatings subjected to post-deposition heat treatment. The presently used treatment temperature at $600^{\circ} \mathrm{C}$ may play a predominant role in enhancing the characteristics of plasma-sprayed HA coatings.

\section{Acknowledgments}

The work was supported by National Science Council of the Republic of China under the contract No. NSC 89-2218E-040-002.

\section{REFERENCES}

1) R. Holmes, V. Mooney, R. Bucholz and A. Tencer: Clin. Orthop. Relat. Res. 188 (1984) 252-262.

2) J. E. Lemons: Clin. Orthop. Relat. Res. 235 (1988) 220-223.

3) K. de Groot, R. Geesink, C. P. A. T. Klein and P. Serekian: J. Biomed. Mater. Res. 21 (1987) 1375-1381.

4) J. E. Dalton and S. D. Cook: J. Biomed. Mater. Res. 29 (1995) 239-245.

5) A. V. Burgess, B. J. Story, D. La, W. R. Wagner and J. P. LeGeros: Clin. Oral Impl. Res. 10 (1999) 245-256.

6) H. Caulier, J. P. C. M. van der Waerden, Y. C. G. J. Paquay, J. G. C. Wolke, W. Kalk, I. Naert and J. A. Jansen: J. Biomed. Mater. Res. 29 (1995) 1061-1069.

7) J. Weng, X. Liu, X. Zhang and Z. Ma: Biomaterials 14 (1993) 225-228.

8) K. A. Gross, C. C. Berndt and H. Herman: J. Biomed. Mater. Res. 39 (1998) 407-414.

9) V. Sergo, O. Sbaizero and D. R. Clarke: Biomaterials 18 (1997) $477-$ 482.

10) C. W. Yang, T. M. Lee, T. S. Lui and E. Chang: Mater. Trans. 46 (2005) 709-715.

11) S. R. Radin and P. Ducheyne: J. Mater. Sci. Mater. Med. 3 (1992) 3342.

12) S. H. Ahn, Y. S. Choi, J. G. Kim and J. G. Han: Surf. Coat. Technol. 150 (2002) 319-326.

13) M. S. Ali, S. Song and P. Xiao: J. Eur. Ceram. Soc. 22 (2002) 101-107.

14) S. H. Maxian, J. P. Zawadsky and M. G. Dunn: J. Biomed. Mater. Res. 27 (1993) 717-728.
15) C. P. A. T. Klein, J. G. C. Wolke, J. M. A. de Blieck-Hogervorst and K. de Groot: J. Biomed. Mater. Res. 28 (1994) 961-967.

16) L. Chou, B. Marek and W. R. Wagner: Biomaterials 20 (1999) 977985.

17) G. L. Darimont, R. Cloots, E. Heinen, L. Seidel and R. Legrand: Biomaterials 23 (2002) 2569-2575.

18) J. Weng, T. Cal, J. Chen and X. Zhang: J. Mater. Sci. Lett. 14 (1995) 211-213.

19) J. Chen, W. Tong, Y. Cao, J. Feng and X. Zhang: J. Biomed. Mater. Res. 34 (1997) 15-20.

20) S. J. Ding, T. H. Huang and C. T. Kao: Surf. Coat. Technol. 165 (2003) 248-257.

21) Y. C. Tsui, C. Doyle and T. W. Clyne: Biomaterials 19 (1999) 20312043.

22) A. K. Lynn and D. L. DuQuesnay: Biomaterials 23 (2002) 1947-1953.

23) C. W. Yang, T. S. Lui, T. M. Lee and E. Chang: Mater. Trans. 45 (2004) 2922-2929.

24) Z. Zyman, J. Weng, X. Liu, X. Li and X. Zhang: Biomaterials 15 (1994) 151-155.

25) Z. E. Erkmen: J. Biomed. Mater. Res. 48 (1999) 861-868.

26) Y. P. Lee, C. K. Wang, T. H. Huang, C. C. Chen, C. T. Kao and S. J. Ding: Surf. Coat. Technol. 197 (2005) 367-374.

27) H. Li, K. A. Kohr and P. Cheang: Biomaterials 23 (2002) 2105-2112.

28) M. Pourbaix: Biomaterials 5 (1984) 122-134.

29) B. O. Flowler, E. C. Moreno and W. E. Brown: Arch Oral Biol. 11 (1966) 477-492.

30) J. Arends, J. Christoffersen, M. R. Christoffersen, H. Eckert, B. O. Fowler, J. C. Heughebaert, G. H. Nancollas, J. P. Yesinowski and S. J. Zawacki: J. Crystal Growth 84 (1987) 515-532.

31) Z. L. Dong, K. A. Khor, C. H. Quek, T. J. White and P. Cheang: Biomaterials 24 (2003) 97-105.

32) J. G. C. Wolke, C. P. A. T. Klein and K de Groot: Bioceramics for maxillofacial applications. In Bioceramics and the human body, ed. by A. Ravaglioli and A. Krajewski (Elsevier, London, UK, 1992) pp. 166180 .

33) H. Ji, C. B. Ponton and P. M. Marquis: J. Mater. Sci. Mater. Med. 3 (1992) 283-287.

34) J. Weng, X. Liu, X. Zhang and X. Ji: J. Mater. Sci. Lett. 13 (1994) 159_ 161.

35) J. Wen, Y. Leng, J. Chen and C. Zhang: Biomaterials 21 (2000) 1339_ 1343.

36) M. Milosevski, J. Bossert, D. Milosevski and N. Gruevska: Ceram. Int. 25 (1999) 693-696.

37) Y. Li, L. Qu and F. Wang: Corros. Sci. 45 (2003) 1367-1381.

38) T. M. Sridhar, U. K. Mudali and M. Subbaiyan: Corros. Sci. 45 (2003) 237-252.

39) K. H. W. Seah, R. Thampuran and S. H. Teoh: Corros. Sci. 40 (1998) 547-556.

40) B. Matthes, E. Broszeit, J. Aromaa, H. Ronkainen, S. P. Hannula, A. Leyland and A. Mathews: Surf. Coat. Technol. 49 (1991) 489-495.

41) E. Celik, I. Ozdemir, E. Avci and Y. Tsunekawa: Surf. Coat. Technol. 193 (2005) 297-302.

42) Y. Cao, J. Weng, J. Chen, J. Feng, Z. Yang and X. Zhang: Biomaterials 17 (1996) 419-424.

43) F. Brossa, A. Cigada, R. Chiesa, L. Paracchini and C. Consonni: J. Mater. Sci. Mater. Med. 5 (1994) 855-857.

44) M. Espanol, V. Guipont, K. A. Khor, M. Jeandin and N. Llorca-Isern: Surf. Eng. 18 (2002) 213-218. 